\title{
Review
}

\section{Progress on superplasticity and superplastic forming in Taiwan during 1987-1997}

\author{
J.C. Huang ${ }^{\mathrm{a},{ }^{*}}$, T.H. Chuang ${ }^{\mathrm{b}}$ \\ ${ }^{a}$ Institute of Materials Science and Engineering, National Sun Yat-Sen University, Kaohsiung, Taiwan \\ ${ }^{\mathrm{b}}$ Institute of Materials Science and Engineering, National Taiwan University, Taipei, Taiwan \\ Received 29 April 1998; received in revised form 19 August 1998; accepted 24 August 1998
}

\begin{abstract}
This paper is to briefly outline the recent research and development activities in the field of superplasticity and SPF/DB applications among academic and industrial community in Taiwan. Academic research activities can be roughly divided into material development and SPF/DB experiments. The material development emphasizes the development of fine-grained materials, resulting in high-temperature superplastic 7075/7475 Al-Zn-Mg alloys and low-temperature superplastic 2090/8090 Al-Li alloys, as well as several high-strain-rate superplastic aluminum matrix composites. The thermomechanical treatments involved include (1) conventional rolling and reheat method, (2) equal channel angular extrusion, (3) reciprocal extrusion, (4) asymmetrical rolling, (5) wedge-shape forging, and (6) directional solidification plus extrusion. The SPF/DB places more weight on forming practices and applications. Titanium base alloys and stainless steel are of more interest. Major breakthrough includes the successful fabrication of high-pressure vessels, spherical coolant containers for infrared detectors, floating balls for level control in chemical industry, internal gas blow forming using inorganic powders, small-scaled SPF/DB straight- or arc-rib reinforced hollow structures, SPF/DB golf heads, and certain special assemblies for electronic products. Limited applications on production lines are undergoing, e.g., the front-head covers for missiles by Military Institute and turbine engine blades by Shan-Tung Aerospace Company. Efforts in applying to titanium golf heads have once been popular, but become less intense due to the recent drop of sale price. The application in electronic industry seems to have promising potential. Finally, the production of extra finegrained aluminum alloys has attracted the attention of local aluminum company recently. (C) 1999 Elsevier Science S.A. All rights reserved.
\end{abstract}

Keywords: Superplasticity; Superplastic forming; Diffusion bonding

\section{Historical background}

This paper is to briefly outline the recent research and development ( $R$ and $D$ ) activities in the field of superplasticity (SP) and superplastic forming and diffusion bonding (SPF/DB) applications among academic and industrial community in Taiwan, R.O.C.

The $\mathrm{R}$ and $\mathrm{D}$ work in this field was initiated in Aerospace Industry Development Center in 1987, intended to fabricate several aluminum aircraft parts for the modified version of F16 fighter, Jing-Gwo generation I. Intensive efforts were made in all aspects in order to reduce weight of the fighter. An international collaboration $\mathrm{R}$ and $\mathrm{D}$ program established with a German company was launched; one item was aimed on the SPF techniques using the $8090 \mathrm{Al}-\mathrm{Li}$ thin sheets. The first SPF hot press machine introduced to Taiwan, made by Murduck company of USA, was installed soon after. It was a

*Corresponding author. scale machine that can produce sizable aircraft parts. Unfortunately, mass applications of SPF products did not continue due to the termination of fabrication plan for Jing-Gwo fighters generation II in 1994.

Since 1987, major superplasticity activities were centered on aircraft or military applications. In addition to the SPF hot press in Aerospace Industry Development Center, there are two others in commercial scales, both also made by Murduck company; one on Materials Development Center of Chung-Shan Institute of Military Science and Technology for making mainly titanium missile-related parts and the other in National Central University for general R and D purpose. Self-designed forming machines in smaller scales and self-written computer programs for blow-gas control are widely available in several universities, such as National Taiwan University, National Sun Yat-Sen University, and Tatung Institute of Technology.

Wide spread of $\mathrm{R}$ and $\mathrm{D}$ activities should be indebted to several stimulating seminar courses; half of them were 
organized by Professor Lee of National Central University, who was a former Ph.D. student of Professor Sherby in Standford. The speakers of the first seminar in 1990 were Professors Ghosh and Hamilton, followed by Professor Sherby in 1993, Professors Bampton and Chandra in 1994, Dr. Nieh in 1997, and Professor Sakuma in 1998.

Workshops on superplasticity among local investigators have also played important roles in information exchange. These include the academic workshops in 1992 and 1994, and industry-oriented promotional workshops in 1992 (by Metal Industries Development Center) and 1994 (by National Taiwan University).

\section{Academic activities}

Academic research activities can be roughly divided into material development, SPF/DB experiments, and superplasticity mechanisms. The group centered in National Sun-Yat University (Huang, Hwang, Kao, and Shih) [1-25] emphasizes the former. The research group centered in National Taiwan University (Chuang, Koo, Wang, and Yang) [26-51] places more weight on SPF/DB and applications. Other academic studies include simulation work in National Central University (Lee) [31,52-54], superplasticity of Al-Li and $\mathrm{Zn}-\mathrm{Al}$ alloys in Nation Tsing Hua University (Chang and Yeh) [55-58], superplasticity of $\mathrm{Al} / \mathrm{Al}_{3} \mathrm{Ni}$ in National Cheng Kung University (Chen and Lui) [59,60], and superplasticity of $\mathrm{Fe}-\mathrm{Al}$ intermetallics (Chu) in National Ocean University [61].

\subsection{Materials development}

The group centered in National Sun-Yat University (Huang, Hwang, Kao, and Shih) emphasizes the development of high-temperature superplastic 7075/7475 Al-Zn$\mathrm{Mg}$ alloys [1,9] and low-temperature superplastic 2090/ 8090 Al-Li alloys $[3,4,7,8,10]$ via patented thermomechanical treatments, in collaboration with China Steel Corp., Aerospace Industry Development Center, Metal Industries Development Center, and National Science Council of Taiwan, ROC.

The joint cooperation between National Sun Yat-Sen University led by Huang and China Steel and Aluminum Corp. in 1991 has resulted in the capability in producing superior superplastic $7075 \mathrm{Al}$ sheets $(1500 \%$ without back pressure at $500^{\circ} \mathrm{C}$ and $2 \times 10^{-4} \mathrm{~s}^{-1}$, as shown in Fig. 1) starting from the DC ingot product of China Aluminum Company in Kaoksiung [9]. The materials have an average grain size of $5 \mu \mathrm{m}$ and were equivalent in comparison with the commercial products fabricated by Kobe Steel or Superform company. For the $8090 \mathrm{Al}-\mathrm{Li}$ alloys, high-temperature superplasticity (HTSP, 600\% without back pressure at 500 $540^{\circ} \mathrm{C}$ and $2 \times 10^{-4} \mathrm{~s}^{-1}$ ) or low-temperature superplasticity (LTSP, $710 \%$ without back pressure at $350^{\circ} \mathrm{C}$ and $8 \times 10^{-4} \mathrm{~s}^{-1}$, as shown in Fig. 2) has been developed in

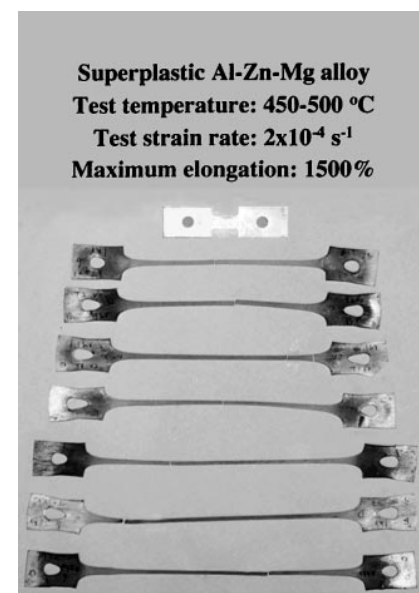

Fig. 1. Examples of the Al-Zn-Mg $7075 \mathrm{Al}$ tensile specimens before and after superplastic loading at $450-500^{\circ} \mathrm{C}$ and $2 \times 10^{-4} \mathrm{~s}^{-1}$, with a maximum elongation of $1500 \%$.

1993 [3,7], starting from the Alcan 8090 non-superplastic thick plates to $50 \mathrm{~mm}$. The (sub)grain dimension before SP loading was around $0.7 \times 0.5 \times 0.2 \mu \mathrm{m}$, as shown in Fig. 3. Transformation from LTSP to HTSP can be easily done [8]. Meanwhile, the LTSP materials have superior properties over the HTSP counterparts in four aspects [7], (1) a higher room temperature strength (510 MPa vs. $450 \mathrm{MPa}$ ) before SP loading, (2) a much higher post-SP strength (500 MPa vs. $380 \mathrm{MPa}$ ) meaning little degradation after loading, (3) a considerably narrower surface solute depletion layer $(7 \mu \mathrm{m}$ vs. $100 \mu \mathrm{m})$, and (4) a much finer grain size after $500 \%$ SP straining $(3.7 \mu \mathrm{m}$ vs. $22 \mu \mathrm{m})$. The improved post-SP properties would be of great values in commercial applications.

Recent involvements in Huang's laboratory were the exploration in high strain rate superplasticity (HRSP) in aluminum matrix composites, dispersion strengthened alu-

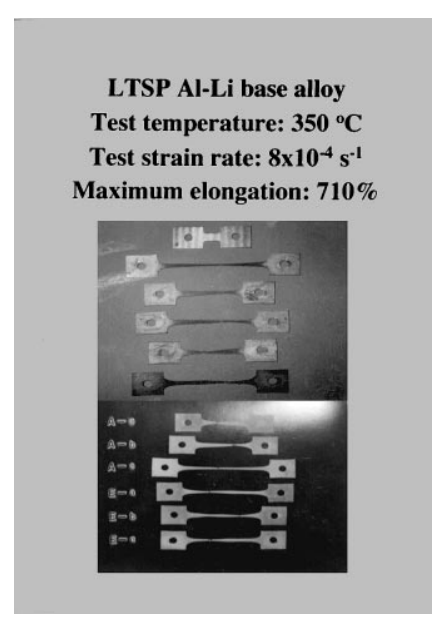

Fig. 2. Examples of the Al-Li-Cu-Mg $8090 \mathrm{Al}$ tensile specimens before and after superplastic loading at $350^{\circ} \mathrm{C}$ and $8 \times 10^{-4} \mathrm{~s}^{-1}$, with a maximum elongation of $710 \%$. 


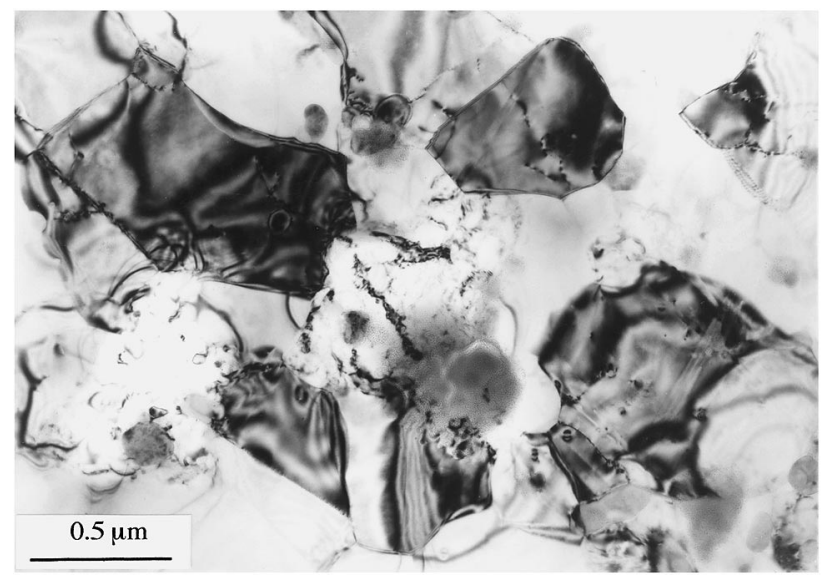

Fig. 3. TEM micrograph showing the (sub)grain structure of the LTSP $8090 \mathrm{Al}$ sheet before SP loading, seen from the rolling plane. The (sub)grain shape was not completely spherical with a dimension of $\sim 0.7 \times 0.5 \times 0.2 \mu \mathrm{m}$. After SP straining to $\sim 50 \%$, the grains gradually become equiaxial.

minum alloys, or pure Al systems. Examples include the 6061 alloys reinforced by different sizes of $\mathrm{SiC}$ particles from $3 \mu \mathrm{m}$ down to $30 \mathrm{~nm}$ (HRSP of $300 \%$ at $580^{\circ} \mathrm{C}$ and $5 \times 10^{-1} \mathrm{~s}^{-1}$ ), pure $\mathrm{Al}$ (HRSP of $250 \%$ at $600-640^{\circ} \mathrm{C}$ and $1 \times 10^{0} \mathrm{~s}^{-1}$ ), and 5083 alloy (LTSP of $400 \%$ at $250^{\circ} \mathrm{C}$ and $2 \times 10^{-3} \mathrm{~s}^{-1}$ ). The fine-grained superplastic materials also tend to possess good combinations of high strength and ductility at room temperature. For example, $510 \mathrm{MPa}$ and $9 \%$ for the LTSP 8090 alloy, $570 \mathrm{MPa}$ and $3 \%$ for the HRSP $2024 / 15 \% \mathrm{SiC}_{(\mathrm{p})}$ composite, $460 \mathrm{MPa}$ and $4 \%$ for the HRSP $6061 / 15 \% \mathrm{SiC}_{(\mathrm{p})}$ composite, and $520 \mathrm{MPa}$ and $5 \%$ for the LTSP 5083 alloy. Finally, a collaboration research with Bampton originally at Rockwell was initiated in 1994, studying the superplasticity of super $\alpha 2 \mathrm{Ti}_{3} \mathrm{Al}$ base alloy (Ti-25atAl-10Nb-3V-1Mo) [12,23]. A high elongation of $1500 \%$ was achieved from the $2 \mathrm{~mm}$ sheets when loaded at $960^{\circ} \mathrm{C}$ and $2 \times 10^{-4} \mathrm{~s}^{-1}$, as presented in Fig. 4. Recent transmission electron microscopy (TEM) results suggested that the phases present during superplastic loading the ordered $\alpha 2, B 2$ and $O$ phases, instead of the originally expected ordered $\alpha 2$ and disordered $\beta$.

Professor Chang's group in National Tsing Hua University also studied the superplasticity of self cast binary or quaternary $\mathrm{Al}-\mathrm{Li}-\mathrm{Cu}-\mathrm{Mg}$ alloys [55]; an elongation of $629 \%$ was reported at $500^{\circ} \mathrm{C}$ and $1.5 \times 10^{-3} \mathrm{~s}^{-1}$ without adding back pressure. Yeh and his student in National Tsing Hua University processed the $\mathrm{Zn}-22 \mathrm{Al}-0.5_{\mathrm{Cu}}$ alloys [57] using his patented reciprocal extrusion method [58], producing fine-grain structures with an average grain size of $0.4 \mu \mathrm{m}$ after 10-times extrusion passes. The resulting $\mathrm{Zn}-\mathrm{Al}$ alloys exhibited $2000 \%$ superplastic elongation at $265^{\circ} \mathrm{C}$ and $7 \times 10^{-2} \mathrm{~s}^{-1}$, as presented in Fig. 5, a typical high-strain rate superplastic behavior in extra fine-grained materials. In Tatung Institute of Technology, Yang and his students studied the role of each step during thermomechanical treatments for the $\mathrm{Zn}-22 \mathrm{Al}$ and $\mathrm{Al}-40 \mathrm{Zn}$ alloys [45]. A

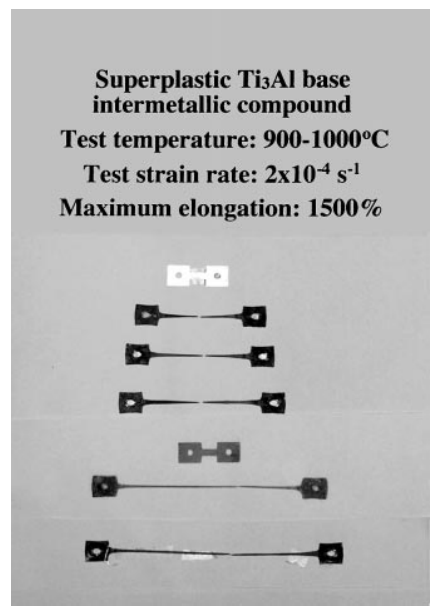

Fig. 4. Examples of the super $\alpha 2 \mathrm{Ti}_{3} \mathrm{Al}-\mathrm{Nb}-\mathrm{Mo}-\mathrm{V}$ tensile specimens before and after superplastic loading at $900-1000^{\circ} \mathrm{C}$ and $2 \times 10^{-4} \mathrm{~s}^{-1}$, with a maximum elongation of $1500 \%$.

high-superplastic elongation around $1000 \%$ was obtained for these alloys at $250-270^{\circ} \mathrm{C}$ and $10^{-3} \mathrm{~s}^{-1}$.

Kao in National Sun Yat-Sen University examined the mechanically alloyed (MA) $\mathrm{Al}_{1} \mathrm{Al}_{3} \mathrm{Ti}$ system [18,22], made from elemental pure $\mathrm{Al}$ and $\mathrm{Ti}$ powders with compositions of Al-4Ti, Al-8Ti, together with extrafine oxides/carbides

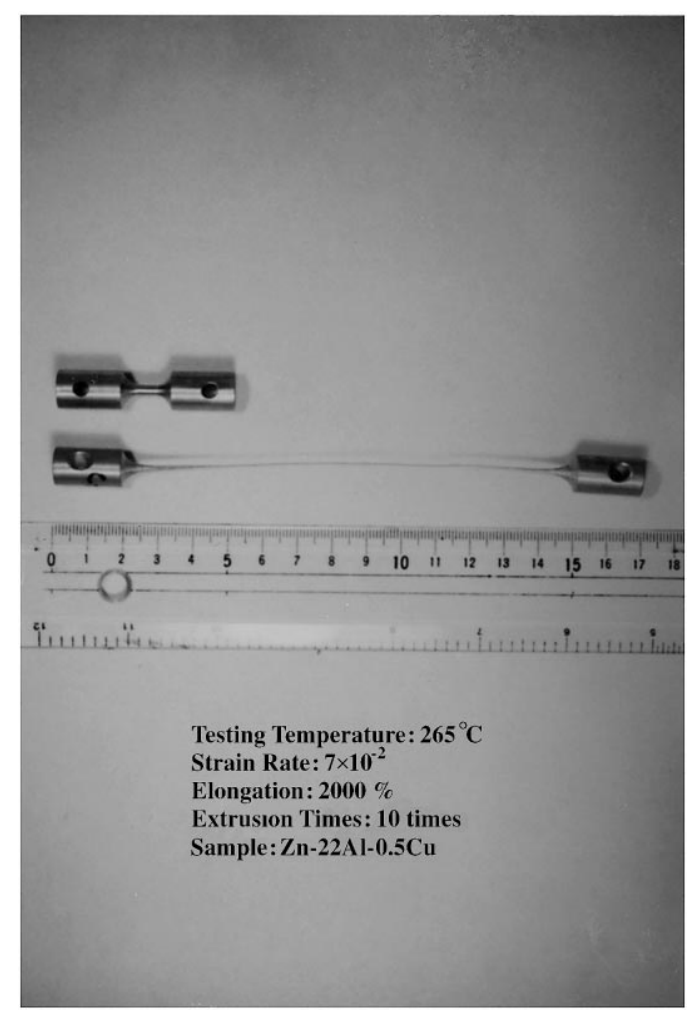

Fig. 5. Examples of the $\mathrm{Zn}-22 \mathrm{Al}-0.5 \mathrm{Cu}$ tensile specimens before and after superplastic loading at $256^{\circ} \mathrm{C}$ and $7 \times 10^{-2} \mathrm{~s}^{-1}$, with a maximum elongation of $2000 \%$ (courtesy of Prof. Yeh of Tsing Hua University). 


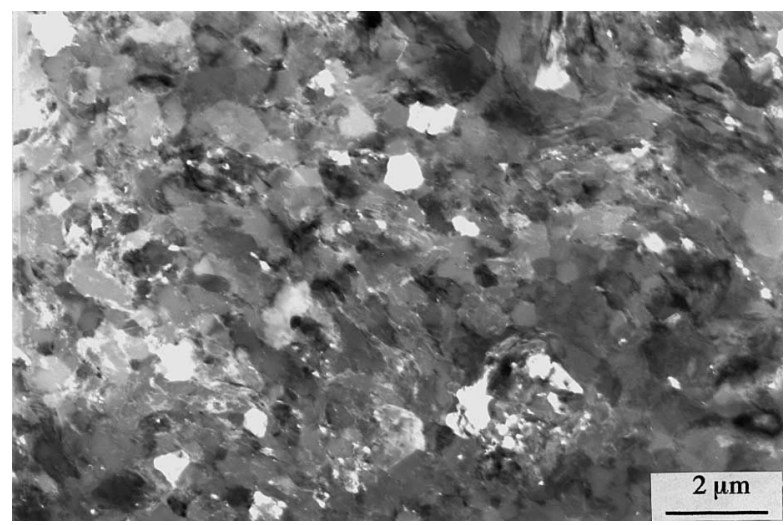

Fig. 6. TEM micrograph showing the grain structure of the MA $\mathrm{Al}-\mathrm{Al}_{3} \mathrm{Ti}$ alloy before SP loading. The equiaxial grain size was around $0.5 \mu \mathrm{m}$. (courtesy of Prof. Kao in Sun Yat-Sen University)

originated from the process control agent of $\mathrm{CH}_{3}\left(\mathrm{CH}_{2}\right)_{16} \mathrm{COOH}$. The resulting oxide/carbide dispersoids, $\mathrm{Al}_{3} \mathrm{Ti}$ particle size and matrix grain size were $30 \mathrm{~nm}, 1 \mu \mathrm{m}$, respectively (Fig. 6). The MA alloys were further hot extruded and then superplastically loaded. The optimum superplastic elongation of $200 \%$ was obtained from the Al-Ti at $620^{\circ} \mathrm{C}$ and $50 \mathrm{~s} \mathrm{~s}^{-1}$, as presented in Fig. 7. The group of Chen and Lui in National Cheng Kung University has started to explore the superplastic behavior of the $\mathrm{Al} / \mathrm{Al}_{3} \mathrm{Ni}$ system $[59,60]$. The $\mathrm{Al} / \mathrm{Al}_{3} \mathrm{Ni}$ eutectic alloys were prepared by directional solidification, followed by hot extrusion to result in fine-grained substructures with strong [ $\left.\begin{array}{lll}1 & 1 & 1\end{array}\right]$ fiber texture. The highest superplastic elongation obtained so far at $500^{\circ} \mathrm{C}$ and $1 \times 10^{-2} \mathrm{~s}^{-1}$ was $300 \%$, as shown in Fig. 8. Such an extended deformation at relatively lower temperature $\left(500^{\circ} \mathrm{C}\right.$ compared with the much higher temperature of $600-640^{\circ} \mathrm{C}$ for similar pure $\mathrm{Al}$ systems reinforced by $\mathrm{Al}_{3} \mathrm{Ti}$ [22] or $\mathrm{AlN}$ [62]) was believed to originated from the 'strain softening resistance' instead

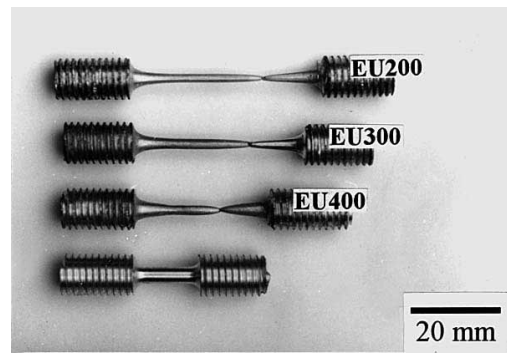

Fig. 8. Examples of the $\mathrm{Al}-\mathrm{Al}_{3} \mathrm{Ni}$ tensile specimens before and after superplastic loading at $500^{\circ} \mathrm{C}$ and $1 \times 10^{-2} \mathrm{~s}^{-1}$, with a maximum elongation of $300 \%$ (courtesy of Prof. Chen of Cheng Kung University).

of strain rate sensitivity $(0.25-0.3)$ [60]. Continuous investigations are now undergoing, and higher superplastic elongations and higher strain rate sensitivity values could be expected when loaded at higher temperatures and strain rates.

In development of superplastic intermetallic compounds, the achievement made by the Koo's group in National Taiwan University $[2,51]$ in producing superplastic $\mathrm{Ti}_{3} \mathrm{Al}$ $\mathrm{Nb}$ and TiAl-Nb alloys should be addressed. The materials were prepared by noncomsumable electrode vacuum arc remelting furnace, followed by two-stage hot rolling. A maximum superplastic elongation of $1100 \%$ for the $\mathrm{Ti}_{3} \mathrm{Al}-$ $10 \mathrm{Nb}$ regular $\alpha 2$ alloy loaded at $975^{\circ} \mathrm{C}$ and $2 \times 10^{-4} \mathrm{~s}^{-1}$ was reported (Fig. 9). Texture influence on the superplastic behavior was observed in their study and the underlying reasons were discussed [42]. Another trial was the team led by $\mathrm{Chu}$ in National Ocean University [61]. The coarsegrained $(700-800 \mu \mathrm{m}) \mathrm{Fe}-27 \mathrm{atAl}$ was found to exhibit superplasticity at temperature above $700^{\circ} \mathrm{C}$, with optimum elongation up to $300 \%$ and strain rate sensitivity of $0.25-$ 0.3 . After superplastic straining, the grain structure became finer to $100-200 \mu \mathrm{m}$ through continuous grains boundary migration [61].

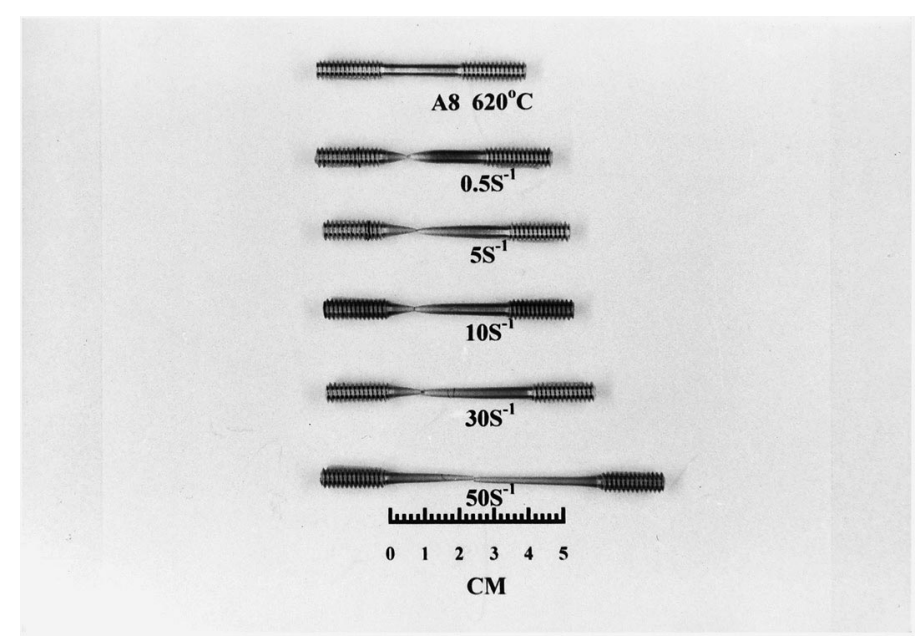

Fig. 7. Examples of the MA Al- $\mathrm{Al}_{3} \mathrm{Ti}$ tensile specimens before and after superplastic loading at $620^{\circ} \mathrm{C}$ and $5 \times 10^{-1}$ to $5 \times 10^{1} \mathrm{~s}^{-1}$, with a maximum elongation 200. (courtesy of Prof. Kao of Sun Yat-Sen University). 


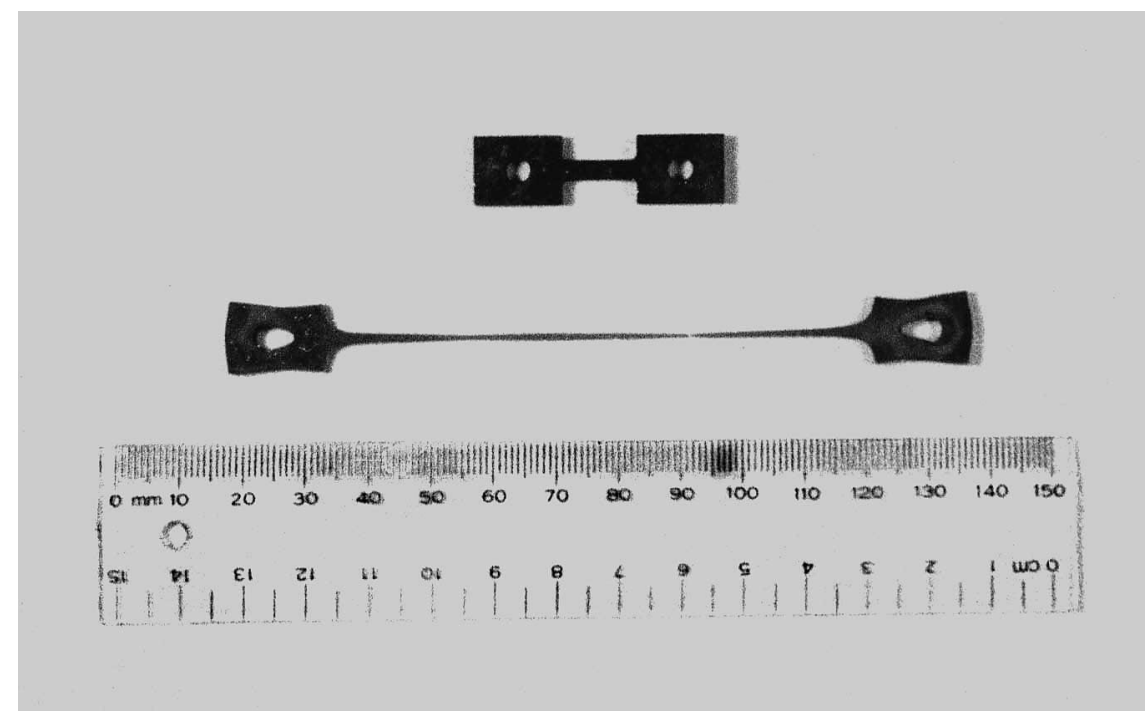

Fig. 9. Examples of the regular $\alpha 2 \mathrm{Ti}_{3} \mathrm{Al}-\mathrm{Nb}$ tensile specimens before and after superplastic loading at $1000^{\circ} \mathrm{C}$ and $2 \times 10^{-4} \mathrm{~s}^{-1}$ with a maximum elongation of $1081 \%$ (courtesy of Prof. Koo of Taiwan University).

Currently, a research group of seven professors is formed, lasting for three years from 1997 to 2000 , headed by Huang and sponsored by National Science Council of Taiwan. Major effects are aimed on the development and characterization of fine-grained materials, such as aluminum composites exhibiting HTSP and HRSP and aluminum alloys possessing LTSP and HRSP. The thermomechanical treatments include (1) conventional rolling and reheat method, (2) equal channel angular extrusion, (3) reciprocal extrusion, (4) asymmetrical rolling, (5) wedge-shape forging, and (6) directional solidification plus extrusion. The materials examined so far comprise $6061 / \mathrm{SiC}_{(\mathrm{p})}, \mathrm{Al} / \mathrm{Ai}_{3} \mathrm{Ni}$, pure $\mathrm{Al}$, Al-Si, 5083 and 6061 alloys.

\section{2. $S P F / D B$ practices}

The research group centered in National Taiwan University (Chuang, Cheng, Koo, Wang, and Yang) places more weight on SPF/DB and applications. Titanium base alloy (Ti-6Al-4V, $\mathrm{Ti}_{3} \mathrm{Al}-\mathrm{Nb}$ ) and stainless steels are of more interest, mostly in collaboration with Materials Development Center of Chung-Shan Institute of Military Science and Technology and National Science Council. Major break-through includes the successful fabrication of high pressure vessel, spherical coolant containers for infrared detectors, floating balls for fluid level control in chemical industry, internal-gas blow forming using inorganic powders, small-scaled SPF/DB straight- or arc-rib reinforced hollow structures, SPF/DB golf heads, and a special design for electronic products [46].

A 5-year research project on SPF/DB was conducted from 1991 to 1996, led by Professor Chuang and sponsored by National Science Council of ROC. Subprogram I conducted by Chuang [26-29,32-37,40,41,43,46,48] investigated the general aspects of SPF/DB. Numerous demo- workpieces were made. For example, the Ti-6Al-4V high pressure vessel (1 mm thick) shown in Fig. 10 was made by SPF, compared with the conventional $6061 \mathrm{Al}$ counterpart ( $5 \mathrm{~mm}$ thick) fabricated by extensive machining plus brazing. This vessel was designed to be filled with coolant for soldier-used infrared detectors. The vessels were first superplastically blow-formed followed by laser welding. With the compatible strength, the new products were much lighter than the previous 6061 ones, which was considered to be important in terms of solider carriage. Another example was

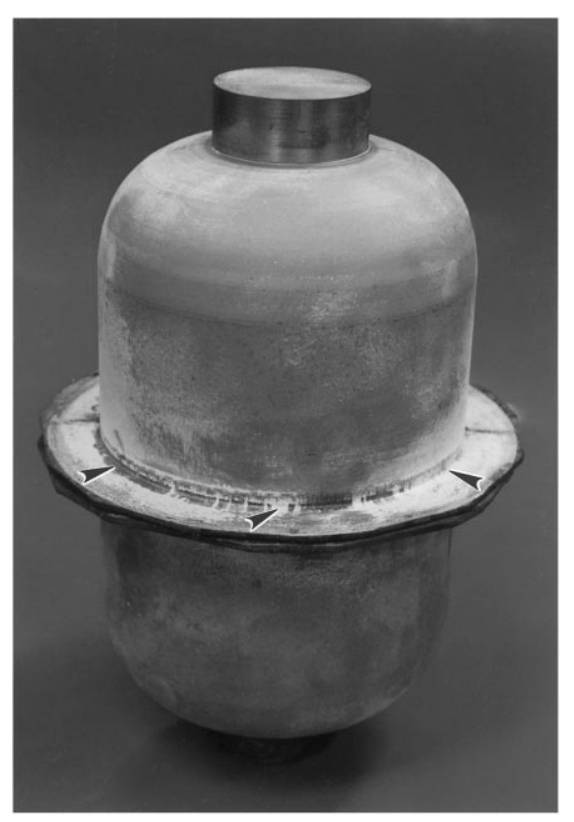

Fig. 10. Ti-6Al-4V high pressure vessel made by SPF/laser-welding, used to fill coolant for soldier-carrying infrared detectors. The laser weld line is indicated by arrows. 


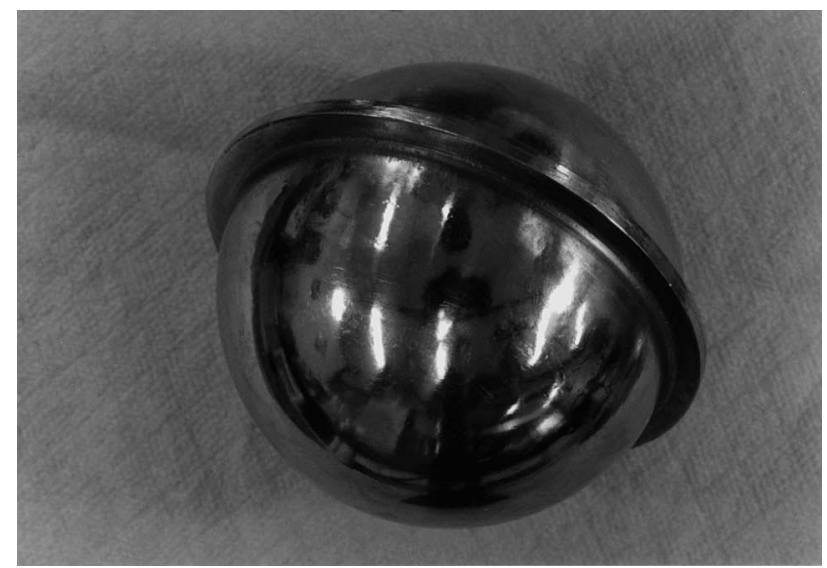

Fig. 11. Ti-6Al-4V spherical coolant containers for infrared detectors made by SPF/DB, used in middle-range missiles.

the Ti-6Al-4V spherical coolant containers for infrared detectors equipped in middle-range missiles (Fig. 11), originally made by SUS 410 stainless steel via machining and fusion welding. The SPF/DB coolant containers can sustain a high pressure of $41 \mathrm{MPa}$ (6000 psi). Furthermore, SPF/DB Ti-6Al-4V floating balls for fluid level control in chemical industry were produced [27], as demonstrated in Fig. 12. The floating balls have the same function as the plastic balls used in flush toilet, but can suffer higher corrosive fluid.

A new SPF forming mean via the decomposition reaction of $\mathrm{CaCO}_{3}+\mathrm{C}$ powders was proposed $[32,37,48]$ by Chuang's laboratory. The forming gas was not provided through inputting outside Ar gas, instead was given by the internal $\mathrm{CO}_{2}$ gas inside the formed piece resulted from the decomposition of $\mathrm{CaCO}_{3}$ powders into $\mathrm{CaO}$ and $\mathrm{CO}_{2}$ at $927^{\circ} \mathrm{C}$ for Ti-6Al-4V and $985^{\circ} \mathrm{C}$ for Superdux 6 stainless steel sheets. Meanwhile, it was found that the $\left(\mathrm{MgCO}_{3}\right)_{4} \mathrm{Mg}(\mathrm{OH})_{2} \cdot x \mathrm{H}_{2} \mathrm{O}$ powders can be decomposed into $\mathrm{CO}_{2}$ and $\mathrm{H}_{2} \mathrm{O}$, and could be used as gas source for the 8090 and $7475 \mathrm{Al}$ alloys at

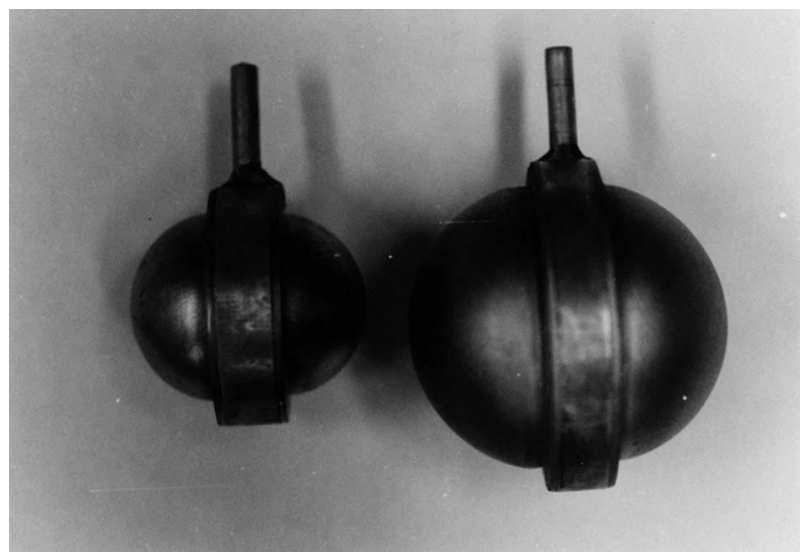

Fig. 12. Ti-6Al-4V floating balls made by SPF/DB used for fluid level control in chemical industry.
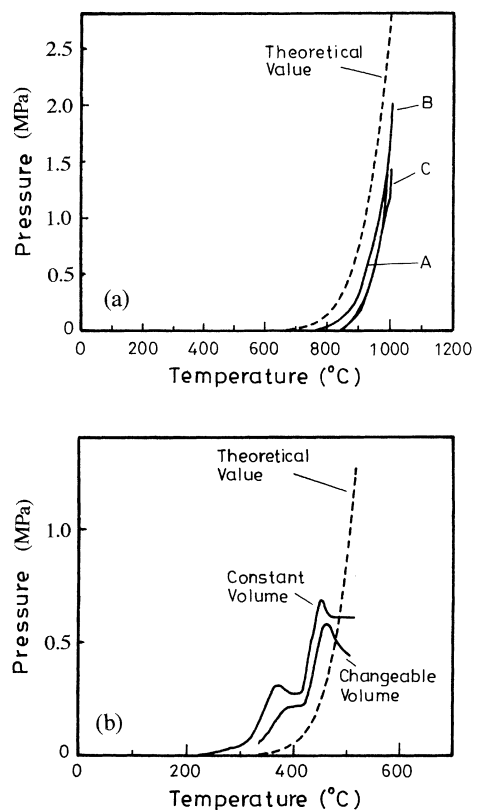

Fig. 13. The internal gas pressure (a) from the decomposition reaction of $\mathrm{CaCO}_{3}+\mathrm{C}$ powders, and (b) resulted from the decomposition reaction of $\left(\mathrm{MgCO}_{3}\right)_{4} \mathrm{Mg}(\mathrm{OH})_{2} \cdot \times \mathrm{H}_{2} \mathrm{O}$ powders as a function of temperature: (-- $)$ theoretical calculations; (- experimental measurements.

$\sim 500^{\circ} \mathrm{C}$. A forming gas pressure to $1.4 \mathrm{MPa}(200 \mathrm{psi})$ or above can be achieved at the corresponding temperatures, as depicted in Fig. 13. Another effort was the low-pressure diffusion with the insertion of a superplastic interlayer between two non-superplastic $\mathrm{Ti}$ or stainless sheets $[33,34]$. For example, the general DB pressure of $7 \mathrm{MPa}$ needed for bonding two non-superplastic Ti-6Al-4V sheets can be reduced down to $2 \mathrm{MPa}$ with a superplastic Ti-6Al$4 \mathrm{~V}$ thin interlayer in-between.

Subprogram II directed by Cheng $[30,31,38,50]$ fabricated the 3-layer perpendicular-rid (Fig. 14) or slanting-rid (Fig. 15) strengthened titanium structures, using the selfmade forming setup and a commercial program ABAQUS/ STANDARD. In order to ensure the efficiency of the SPF/ DB workpiece finite element analyses were performed in terms of product design, SPF/DB process design, and SPF pressure and thickness simulation. The program dealt with the determination of the eigenfrequency and eigenmodes, local bucking of the blade face, local stress concentration, and impact response. Joint efforts with a local golf club factory in fabrication and computer simulation of $\mathrm{Ti}$ golf heads have been and are still being made using the patented know-how [44].

Subprogram III headed by Wang [47] examined the effects of temporary hydrogen charging on the superplastic behavior of Ti base alloys and shape memory $\mathrm{Cu}-\mathrm{Zn}-\mathrm{Al}-\mathrm{Zr}$ alloys. It was found that under an optimum combination of hydrogenation temperature and hydrogen concentration SPF of Ti-6Al-4V alloys proceeded at much higher rates. Subprogram IV directed by Koo [42,51] developed the $\mathrm{Ti}_{3} \mathrm{Al}-\mathrm{Nb}$ superplastic sheets with $8-12 \mathrm{atNb}$, as introduced 

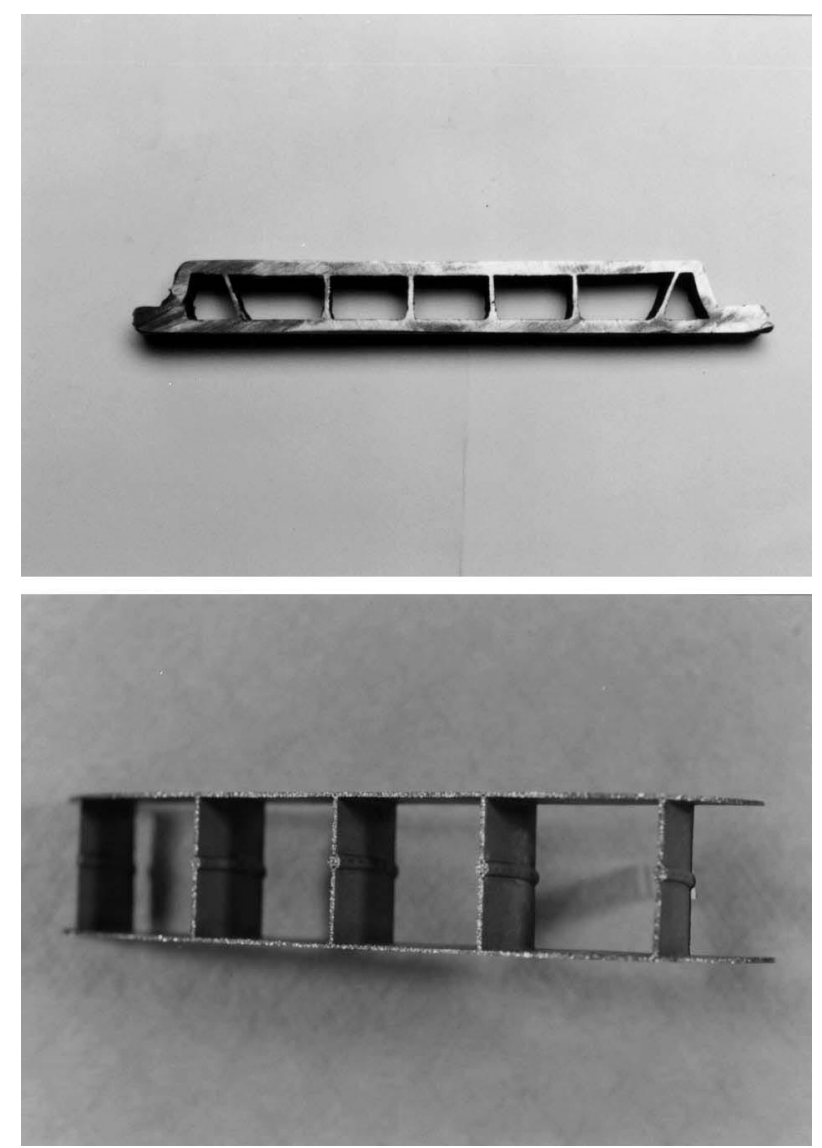

Fig. 14. Examples of the three-layer, perpendicular-rid strengthened Ti6Al-4V structure using SPF/DB technique. (courtesy of Prof. Cheng of Taiwan University)

above. Subprogram V directed by Yang [49] emphasized the solid state and transient liquid phase diffusion bonding of various aluminum alloys. Interlayers of $\mathrm{Zn}$ were prepared through mill rolling (to $20 \mu \mathrm{m}$ in thickness) or electroplating $(3-10 \mu \mathrm{m})$ methods. Parameters under examination included the surface roughness, interlayer thickness, base alloy composition, bonding temperature, time, pressure, and vacuum condition. Optimum shear lap bond strength, using solid DB under a vacuum of $10^{-4}$ Torr, to $90 \%$ of that of the base alloy has been achieved for the $7475 \mathrm{Al}$ system.

In addition to solid state and transient liquid phase diffusion for superplastic materials, brazing [26,40,41], electron beam welding $[6,17,20]$, and laser beam welding $[16,17,20]$ have been utilized in joining superplastic thin sheets in National Taiwan University (Chuang) and Sun YatSen University (Huang). Solidification cracking and porosity were identified to be the major detrimental factors for aluminum superplastic sheets. Typically, a joining efficiency of the weld strength above $85 \%$ of the parent materials can be obtained. However, recent observations suggested that even though the weld strength can be sustained, the toughness of a notched electron-beam-welded bar specimen tended to be only $30 \%$ that of the parent alloy. Precaution should be taken care of.
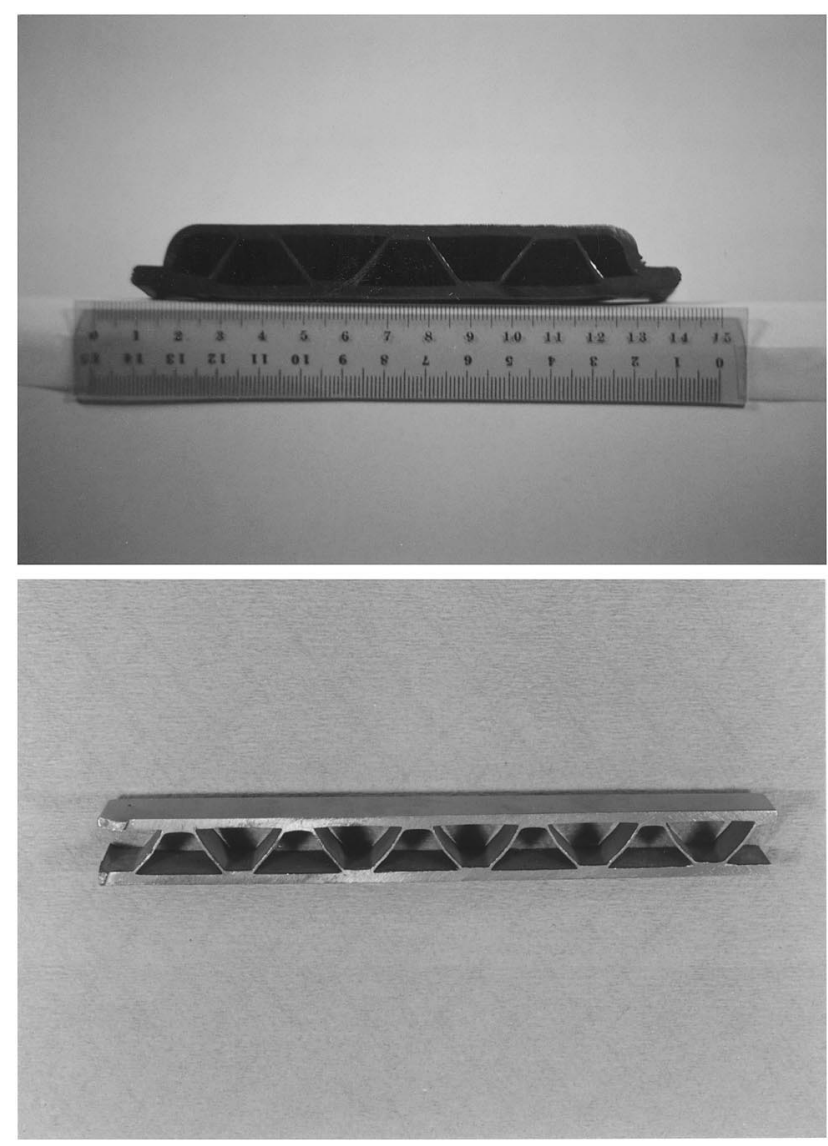

Fig. 15. Examples of the three-layer slanting-rid strengthened Ti-6Al-4V structure using SPF/DB technique (courtesy of Prof. Cheng of Taiwan University).

The group under Professor Lee in National Central University took advantage of the Murduck SPF hot press and performed systematic blow forming for aluminum and titanium alloys. Due to the size of their hot press, much larger workpiece can be made. Sandwich panels of three- or four-piece Ti-6Al-4V SPF/DB structures have been tried [52-54] with special efforts on die and gas tube design. Extensive computer simulation work on the dimple or grooving effect in SPF/DB pieces was conducted [31].

Hwang's and Huang's groups in National Sun Yat-Sen University also made great efforts on SPF/DB of aluminum alloys. A series of self-written computer programs for pressure profiles and thickness distributions, based on finite difference methods, have been completed in simulation and comparison with experimental observations $[2,5,11,14,19,24]$. The program incorporated the strain hardening exponent ( $n$-value) additionally into the constitutive equation for the simulation, i.e., the equation $\sigma=K^{\prime} \varepsilon^{n} \dot{\varepsilon}^{m}$ was used. The model also incorporates the non-uniform thinning effect during free bulging [19]. In addition, the effects of different friction coefficients at different locations of the formed part can be considered, using different friction coefficients, such as $\mu=0$ (complete sliding), $\mu=0.01-0.1$ (different degrees of partial sliding), 


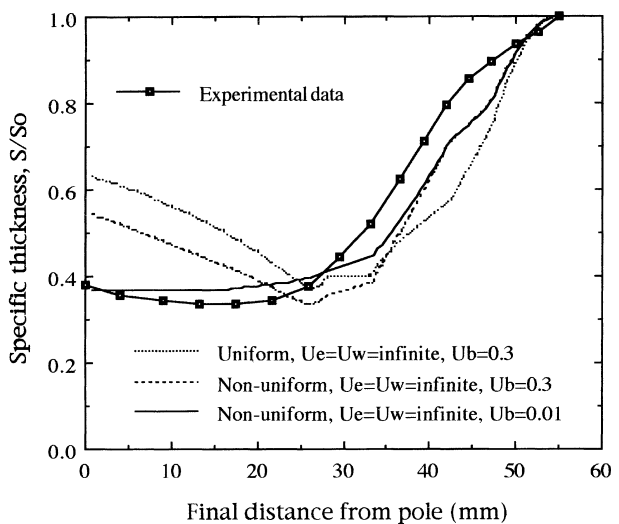

Fig. 16. The thickness distribution of the $8090 \mathrm{Al}-\mathrm{Li}-\mathrm{Cu}-\mathrm{Mg}$ superplastic thin sheet close-die SPFed at $525^{\circ} \mathrm{C}$ to a depth-to-diameter ratio of $1 / 3$. The experimental data fit best with the computer simulation using nonuniform thinning during free bulging and friction coefficients of $\mu=\infty$ for the die entry and die wall region and $\mu=0.01$ for the die bottom regime.

or $\mu=\infty$ (complete sticking) for each selected position $[5,11,19,24]$. It was found that the lubrication effect after the onset of SPF becomes different at different positions of the formed part. Due to the lubricant sliding downwards, there is almost no lubrication at the die entry (hence $\mu \sim \infty$ ) and near complete lubrication and free specimen sliding at the central bottom region (hence $\mu \sim 0$ ). The comparison between theoretically predicted and experimentally measured thickness distribution for SPF aluminum sheets is shown in Fig. 16. The best agreement was found in those cases where $\mu \sim \infty$ is used for the die entry and side wall regions and $\mu \sim 0.01$ for the central bottom regime. Finally, the variable strain rate path for blow forming has been examined [14]; a similar work has also been published by the Yang's group [39].

\subsection{Superplasticity mechanisms}

Chang and Yeh in National Tsing Hua University proposed to use the curvature of tensile-loaded specimens to define the superplastic behavior [55], instead of the common superplastic elongation due to the lack of universally specified gauge length. The curvature can describe the degree of necking within the gauge section. Furthermore, through the derived equations for curvature, strain rate sensitivity and tensile elongation, systematic relationship can be revealed [56] as depicted in Fig. 17. The dotted line on the top refers to the maximum tensile elongation with a given strain rate sensitivity $m$-value; e.g., a maximum elongation of $\sim 600$ is theoretically predicted for $m=0.5$ under the given geometry conditions.

The rate controlling constitutional equations have been examined in several superplastic materials in Huang's and Kao's group in National Sun Yat Sen University. The combined roles of dislocation slip creep and grain boundary sliding (GBS) were considered for the LTSP 8090 and super

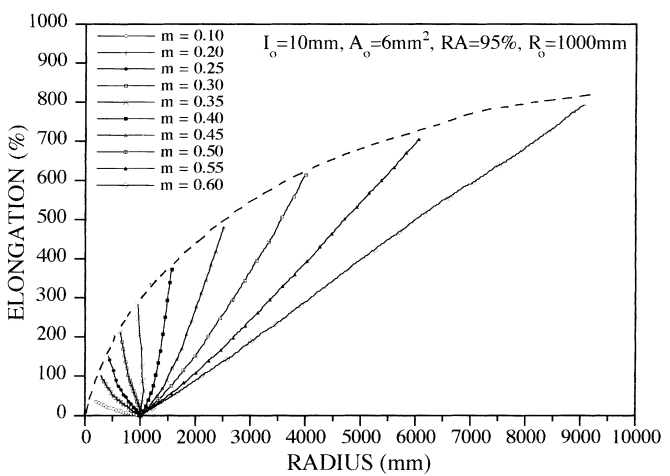

Fig. 17. The relationship of tensile superplastic elongation, specimen gauge curvature radius, and strain rate sensitivity $m$-values. The dashed line represents the theoretically predicted superplastic elongations based on the characteristic $m$-values (courtesy of Prof. Chang of Tsing Hua University).

$\alpha 2$ alloys [7,23]. The activation of cooperative and individual GBS during each stage of superplastic tensile straining or superplastic forming, as well as the topography of grain boundary sliding offsets, grain rotation angles, formation of striated bands or fibers, cavity distribution, cavity formation mechanisms, and contribution of grain boundary sliding or grain separation to the overall strain, were traced using scanning or transmission electron microscopy [7,25] shown, e.g., in Fig. 18. Special emphasis was laid on the deformation mechanisms during the initial stage of superplastic straining, and the role of liquid phase observed in HRSP materials. Chen and Lui's group in National Cheng Kung University found high elongation with ideal plastic behavior following the initial work hardening stage in their strongly [1 111 l] textured $\mathrm{Al}_{-} \mathrm{Al}_{3} \mathrm{Ni}$ alloys [60]. Interestingly, the strong fiber texture did not get altered significantly after $300 \%$ superplastic elongation $[59,60]$ contrary to most superplastic alloys. The extended elongation was believed

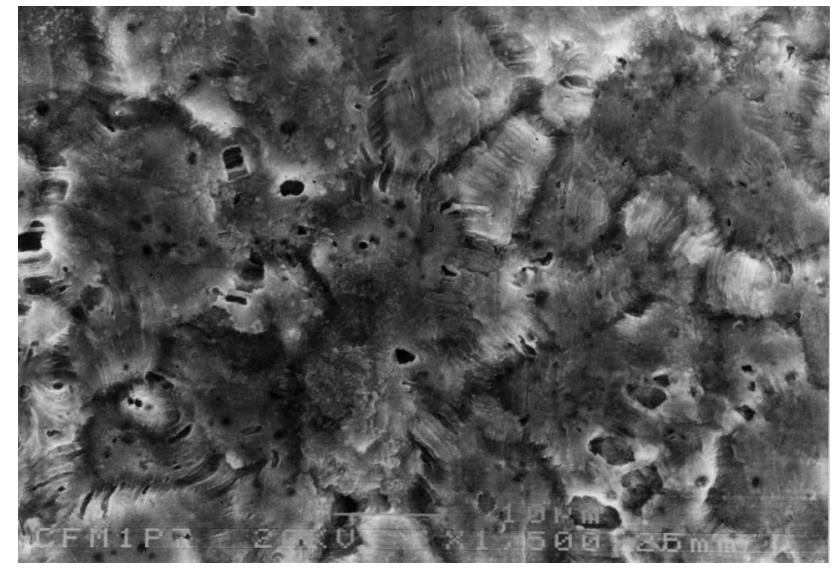

Fig. 18. Typical SEM micrograph of the surface topography observed from a SPFed $8090 \mathrm{Al}-\mathrm{Li}-\mathrm{Cu}-\mathrm{Mg}$ superplastic thin sheet after a thickness strain of 1.0. The grain boundary sliding, grain rotation, prescribed maker line offset, formation of striated bands and fibers, and cavitation distribution were under examination. 
to originate from the 'strain softening resistance' instead of strain rate sensitivity, which is low (within 0.25-0.3). The plasticity was explained in terms of Taylor factor arguments for the primary slip and multiple slip for subgrains of different orientations [60].

Koo's team in National Taiwan University rationalized the superplasticity in their $\mathrm{Ti}_{3} \mathrm{Al}-\mathrm{Nb}$ alloys in terms of GBS accommodated by dislocation slip in hexagonal $\alpha 2$ phase [42]. Since the major texture component for the $\alpha 2$ phase is the (0002)[2020], one set of the dislocations with Burger's vector $b=1 / 3[\overline{1} 2 \overline{1} 0]$, which is parallel to the rolling, tend to possess the highest resolved stress and hence become more effective in accommodation for GBS. This results in the anisotropic superplasticity, i.e., a higher superplastic elongation when loading the specimen along its rolling direction.

\section{Industry applications}

The $\mathrm{R}$ and $\mathrm{D}$ progress has been announced to local industrial circles through a few open seminars. The one in 1994 held in National Taiwan University attracted over 150 attendants from 80 local manufacture companies, including fields in aerospace and aircraft manufacture, military, steel making, forging, electric power, toy, microelectronics, golf club maker, heat treatment, and ship building, etc.

Nevertheless, limited applications are underway as yet. In Aero Industry Development Center, major efforts were made on the SPF process design, post-SPF material property evaluation and quality control for a number of aluminum aircraft parts. Examples include the cover box measuring $390 \times 304 \times 92 \mathrm{~mm}$ and the flap substructure measuring $660 \times 450 \times 20 \mathrm{~mm}$ [63]. A 200-pages industry working guideline for SPF was recently completed for reference, comprising seven chapters, i.e., SPF development and applications, aluminum superplasticity, aircraft SPF-part design, processing and simulation analysis, die and tool design, SPF processing technology, and sample illustration.

In Chung Shan Institute of Military Science and Technology, the major SPF product under fabrication is the fronthead covers for missiles, as shown in Fig. 19. The assembly was first made by hot pressing under optimum superplastic conditions using superplastic Ti-6Al-4V, followed by electron beam welding in vacuum. The SPF/DB Ti-6Al-4V spherical coolant containers for infrared detectors (Fig. 11) have been routinely made in production lines for middle-range missiles by Chung Shan Institute of Military Science and Technology. Another example is the hollow fan Hub (Fig. 20) made by Shan-Tung aerospace company, using DB technique from Ti-6Al-4V forged rings. The hollow fan hub is a key piece in the Pratt and Whitney JT9D gas turbine engine, and Boeing B747 and B767 as well as DC-10. Diffusion bonding was applied for bonding a spacer (for dovetail and turbine fans) onto this hollow hub
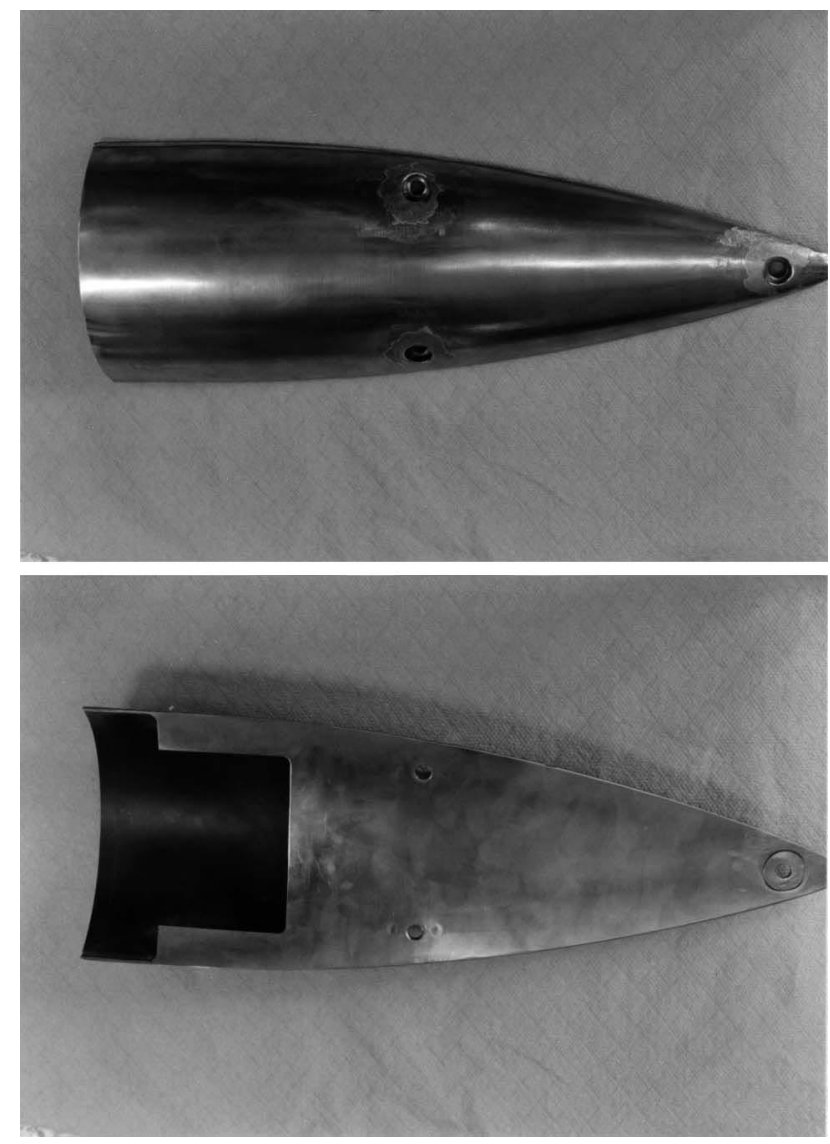

Fig. 19. The (a) front view, and (b) back view of the front-head covers for missiles made of Ti-6Al-4V superplastic sheets (courtesy of Chung Shan Institute of Science and Technology).

measuring $915 \mathrm{~mm}$ in outer diameter, $203 \mathrm{~mm}$ in inner diameter and $254 \mathrm{~mm}$ in thickness.

Metal Industry Development Center has set SPF/DB techniques as one of the five center development goals.

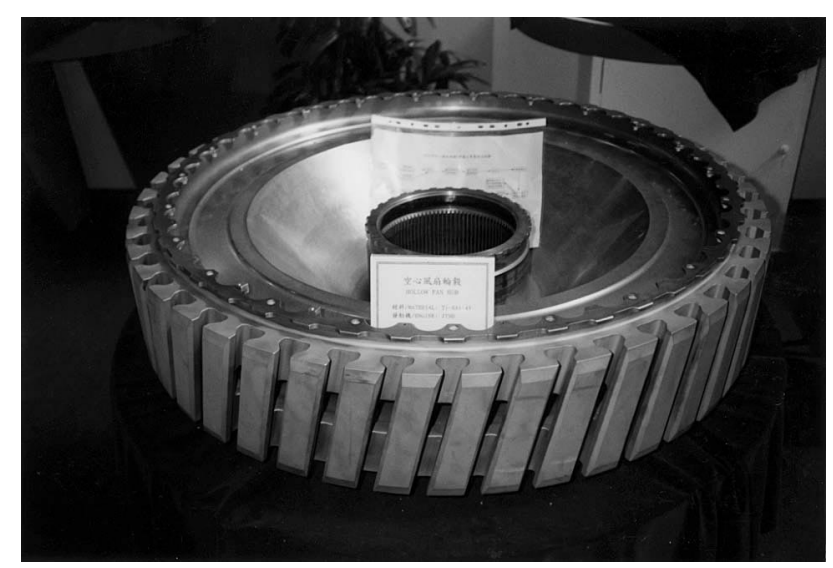

Fig. 20. The hollow fan hub made from Ti-6Al-4V forged rings, applying the DB technique for bonding a spacer (for dove tail and turbine fans) onto this hollow hub measuring $915 \mathrm{~mm}$ in outer diameter, $203 \mathrm{~mm}$ in inner diameter and $254 \mathrm{~mm}$ in thickness (courtesy of Shan-Tung aerospace company). 
The results have been shared with local industries. A local company started to fabricate aluminum food trays for serving in commercial aircrafts using SPF technique. In addition to local technical support, collaboration with Beijing Research Institute of Mechanical and Electric Technology has been established in producing the aluminum trays. Efforts in applying SPF and/or DB to titanium golf heads have once been popular. Currently there are still a few companies which continue the effort, but the motivation seems to decrease due to the recent drop in sale prices. Some special applications using SPF coupled with different means of bonding techniques in electronic industry seem to have promising potential. Due to business competition and patent restriction, it is not suitable to disclose related information yet. Finally, the production of extra fine-grained aluminum alloys has attracted the attention of local aluminum companies lately.

\section{Closing remarks}

The $\mathrm{R}$ and $\mathrm{D}$ progress made during the past 10 years has advanced the understanding for superplasticity from near zero to a status critical for future directions. Compared with the fast growing global research achievements in superplasticity, the advance during the past decade in Taiwan has not been impressive. The internal gas pressure forming was an interesting invention and unique process alternative, which should earn its credit. The continuous efforts on developing superplastic materials, particularly aluminum alloys, might be the main achievement on the worldwide standard. It is expected that further breakthrough along this direction should be accomplished within the next few years, using extensive thermomechanical treatments, equal channel angular extrusion, or reciprocal extrusion. In addition to producing superplastic aluminum alloys, it is suggested that parallel explorations on several new related fields should be initiated, these includes, for example, the superplastic-like behavior of supercooled liquid observed in bulk amorphous $\mathrm{Zr}$-Al-Ti-Cu-Ni (or similar) alloys [64,65] and the 'near-net-shape' injection molding technique for $\mathrm{Mg}$ base alloys.

However, if still no mass production of SPF/DB parts could be achieved, research along this line would soon shrink appreciably. Potential utilization in Taiwan might be in either the electronic or the motorcycle factories. It is hoped that the application of superplastic sheets to shielding covers for electronic instruments can be spread in Taiwan soon. As the HRSP and LTSP are supposed to be simultaneously present in $\mathrm{Al}-\mathrm{Li}$ or $\mathrm{Al}-\mathrm{Ci}$ base alloys processed via equal channel angular extrusion at $200-400^{\circ} \mathrm{C}$ [66], applications in motorcycle or automobile industry could have chance for a breakthrough. A few Taiwanese companies seem to have willingness in following the future movement of Japanese major companies.

\section{Acknowledgements}

Special thanks are due to the long sponsorships of National Science Council, Aerospace Industry Development Center and Materials Development Center of Chung Shan Institute of Science and Technology, Metal Industry Development Center, China Steel Corp., and China Aluminum Company. The kind provision of related information from Professors Cheng, Koo, Lee, Yang, Kao, Hwang, Chen, Chang, Yeh, Mr. Tien of Aero Industry Development Center, and Mr. Shyr of Shan-Tung Aerospace Company are gratefully acknowledged. It is also our pleasure to acknowledge the diligent commitments of numerous graduate students in this interesting field. This paper is sponsored under the project No. NSC 87-2216-E-110-017.

\section{References}

[1] H.P. Pu, S.H. Yen, J.C. Huang, P.W. Kao, Evaluation on superplasticity in $\mathrm{Al}-\mathrm{Li}$ and $\mathrm{Al}-\mathrm{Zn}-\mathrm{Mg}$ base alloys, Proc. Int. Conf. on Superplasticity in Advanced Materials (ICSAM-91), Osaka, Japan, 1991, p. 429.

[2] T.R. Chen, J.C. Huang, The forming behavior and post-form properties of superplastic 8090 Al-Li thin sheets, Chinese J. Mater. Sci. 25 (1993) 34.

[3] H.P. Pu, J.C. Huang, Low-temperature superplasticity in 8090 Al-Li alloys, Scripta Mater. 28 (1993) 1125.

[4] H.P. Pu, J.C. Huang, G.R. Su, Low-temperature superplasticity in 8090 Al-Li base alloys, ROC patent No. 062260, 1993.

[5] T.R. Chen, J.C. Huang, G.M. Liauo, Y.M. Hwang, Lubrication effect in superplastic forming of Al-Li thin sheets, Scripta Metall. Mater. 31 (1994) 309

[6] J.C. Huang, Y.D. Shen, N.J. Ho, Characterization of the electron beam welding of superplastic 8090 Al-Li alloys, Mater. Sci. Technol. 10 (1994) 647

[7] H.P. Pu, F.C. Liu, J.C. Huang, Characterization and analysis lowtemperature superplasticity in 8090 Al-Li alloys, Metall. Mater. Trans. 26A (1995) 1153

[8] H.P. Pu, J.C. Huang, Processing routes for intertransformation between low-temperature and high-temperature superplasticity in 8090 Al-Li alloys, Scripta Metall. Mater. 33 (1995) 383.

[9] H.P. Pu, J.C. Huang, H.C. Shih, S.Y. Yen, Thermomechanical treatments for making superplastic 7075 and $7475 \mathrm{Al}$ sheets, ROC patent No. 07043, 1995.

[10] H.P. Pu, J.C. Huang, H.C. Shih, Processing routes for intertransformation between low-temperature and high-temperature superplasticity in 8090 Al-Li alloys, ROC patent No. 073148, 1995.

[11] Y.M. Hwang, J.M. Liew, T.R. Chen, J.C. Huang, Analysis of superplastic blow-forming in a circular close-die, J. Mater. Processing Technol. 57 (1996) 360.

[12] H.C. Fu, J.C. Huang, Superplasticity behavior of super- $\alpha 2 \mathrm{Ti}_{3} \mathrm{Al}$ intermetallic compound, Chinese J. Mater. Sci. 28 (1996) 28

[13] T.R. Chen, G.J. Peng, J.C. Huang, Quench sensitivity and its effects on mechanical properties of the 8090 Al-Li superplastic thin sheets, Mater. Sci. Forum, 217-222 (1996) 1073.

[14] T.R. Chen, J.C. Huang, Y.M. Hwang, Fundamental characterization of hemisphere free bulging using superplastic 8090 Al-Li sheets, Mater. Sci. Technol. 12 (1996) 49.

[15] T.R. Chen, G.J. Peng, J.C. Huang, Low-quench sensitivity in superplastic 8090 Al-Li thin sheets, Metall. Mater. Trans. 27A (1996) 2923 
[16] M.F. Lee, J.C. Huang, N.J. Ho, Microstructure and mechanical characterisation of laser-beam welding of a $8090 \mathrm{Al}-\mathrm{Li}$ thin sheet, J. Mater. Sci. 31 (1996) 1455.

[17] J.C. Huang, S.C. Chen, M.F. Lee, Y.D. Shen, Joining efficiency evaluation of superplastic $8090 \mathrm{Al}-\mathrm{Li}$ thin sheets using electron or laser beam welding, Mater. Sci. Forum, 217-222 (1996) 1697.

[18] Y.C. Cheng, S.H. Wang, P.W. Kao, C.P. Chang, Microstructures and

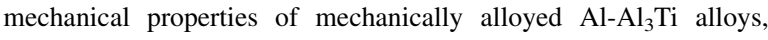
Mater. Sci. Forum, 217-222 (1996) 1891.

[19] Y.M. Hwang, J.S. Yang, T.R. Chen, J.C. Huang, Analysis of superplastic sheet metal forming in a circular close-die considering nonuniform thinning, J. Mater. Processing Technol. 65 (1997) 215.

[20] S.C. Chen, J.C. Huang, The lap-shear and t-peel strength of overlap joints of superplastic 8090 Al-Li sheets bonded by electron-beam and laser-beam welding, Mater. Sci. Tech. 13 (1997) 143.

[21] B.Y. Lou, J.C. Huang, H.P. Pu, Processing development and property characterization for aluminum alloys or composites exhibiting lowtemperature or high-rate superplasticity, Proc. Thermec '97, Wollongong, Australia, 1997, p. 1853.

[22] L.W. Yang, P.W. Kao, High-temperature tensile behavior MA Al-Ti alloy at high strain rate, Proc. Thermec '97, Wollongong, Australia, 1997, p. 1457

[23] H.C. Fu, J.C. Huang, C.D. Wang, C.C. Bampton, Evolution of microstructure and superplastic deformation mechanism in super- $\alpha 2$ $\mathrm{Ti}_{3} \mathrm{Al}$ base alloys, Acta Mater. 46 (1998) 465.

[24] Y.M. Hwang, J.S. Yang, T.R. Chen, J.C. Huang, E.U. Wu, Analysis of superplastic blow-forming in a conical closed die, Int. J. Mech. Sci. 40 (1998) 867.

[25] T.R. Chen, J.C. Huang, Grain boundary sliding seen in multiaxial forming and uniaxial tensile tests, Metall. Mater. Trans., 29A 1998 , in press.

[26] T.H. Chuang, Combination processing method of superplastic forming and barzing, German patent No. DE4200047C2, ROC patent No. 54545, 1992.

[27] T.H. Chuang, Processing method for Ti hollow floating ball, ROC patent No. 63830, 1993.

[28] J.S. Shyu, T.H. Chuang, Studies on the superplastic forming of Superdux 64 stainless steel, J. Chinese Mater. Sci. 26 (1994) 289.

[29] J.S. Shyu, T.H. Chang, Comparison of superplastic formability between Ti-6Al-4V and Ti-6Al-6V-2Sn alloys, J. Chinese Mater. Sci 27 (1994) 130

[30] J.H. Cheng, A procedure for designing initial thickness variation for superplastic free inflation, Int. J. Mech. Sci. 36 (1994) 981.

[31] J.H. Cheng, S. Lee, Methods for resolving grooving problems in parts manufactured from combined diffusion bonding and superplastic forming process, J. Mater. Processing Technol. 45 (1994) 249.

[32] T.H. Chuang, J.S. Shyu, Superplastic forming using internal pressure method, German patent no. DE4341281C2, US patent No. 5449109 , ROC patent No. 64904, 1994.

[33] M.S. Yeh, T.H. Chuang, Low-pressure diffusion bonding of SAE 316 stainless by inserting a superplastic interlayer, Scripta Metall. Mater. 33 (1995) 1277.

[34] J.S. Shyu, T.H. Chuang, Diffusion bonding of Ti-6Al-4V alloy under low pressure, J. Chinese Mater. Sci. 27 (1995) 141

[35] M.S. Yen, C.W. Tsau, T.H. Chuang, Evaluation of superplastic formability of SP-Inconel 718 superalloy, J. Mater. Eng. Perf. 5 (1996) 64

[36] J.S. Shyu, T.H. Chuang, Diffusion bonding/superplastic forming of Ti-6Al-6V-2Sn/SUS 304 stainless steel/Ti-6Al-6V-2Sn, J. Mater. Eng. Perf. 5 (1996) 84.

[37] J.S. Shyu, T.H. Chang, Superplastic forming by decomposition of $\left(\mathrm{CaCO}_{3}+\mathrm{C}\right)$ and $\mathrm{MgCO}_{3}$, J. Mater. Eng. Perf. 5 (1996) 387.

[38] J.H. Cheng, The determination of material parameters from superplastic inflation tests, J. Mater. Processing Technol. 58 (1996) 233.

[39] C.F. Yang, L.H. Chiu, S.C. Lee, Superplastic forming of $7475 \mathrm{Al}$ alloy by variable-pressure blowing, Scripta Metall. Mater. 34 (1996) 1555 .
[40] M.S. Yeh, T.H. Chuang, The SPF/brazing process for Inconel 718 SPF superalloy components, Welding Res. Suppl. May, 1997, p. 1975.

[41] M.S. Yeh, T.H. Chuang, Effects of applied pressure on the brazing of superplastic Inconel 718 superalloy, Metall. Mater. Trans. 28A (1997) 1367.

[42] Y.T. Wu, C.H. Koo, Effect of texture on the superplasticity of Ti-25Al-10Nb alloy, Intermetallics 5 (1997) 29.

[43] T.H. Chuang, Y.S. Tsing, Forming method through superplastic forging, ROC patent No. 82113, 1997.

[44] J.H. Cheng, A New Structure for Golf Head and the Method of its Manufacture, ROC patent No. 83104076, US patent No. 5643108, 1997.

[45] C.F. Yang, L.H. Chiu, Y.P. Sheu, Effects of thermomechnical treatment on superplasticity of $\mathrm{Zn}-22 \% \mathrm{Al}$ alloy, J. Mater. Manufacturing Processes 12 (1997) 199.

[46] T.H. Chuang, J.H. Cheng, W.H. Wang, C.F. Yang, C.H. Koo, Research on the superplastic forming and diffusion bonding of aerospace materials, Proc. Natl. Sci. Council, ROC(A) 22 (1998) 103.

[47] T.Y. Fang, W.H. Wang, The influence of temporary alloying of hydrogen on the microstructure and superplasticity of Ti-6Al-4V alloy, Proc. Natl. Sci. Counc., ROC(A) 22 (1998) 116.

[48] T.H. Tsai, J.S. Shy, T.H. Chuang, Scale formation on Ti-6Al-4V and Superdux 65 stainless steel after superplastic forming by decomposition of $\left(\mathrm{CaCO}_{3}+\mathrm{C}\right)$, Proc. Natl. Sci. Council, ROC(A) 22 (1998) 126.

[49] C.F. Yang, L.H. Chiu, S.C. Lee, J.Y. Sun, Solid state and transient liquid phase diffusion bonding of Al-Zn-Mg alloy, Proc. Natl. Sci. Council, ROC(A) 22 (1998) 132

[50] J.H. Cheng, W.J. Chen, W.S. Tang, S.B. Fengchiang, G.C. Hsiu, H.Y. Change, Design, simulation, manufacture and strength characterization of SPF/DB parts, Proc. Natl. Sci. Council, ROC(A) 22 (1998) 142 .

[51] Y.T. Wu, C.H. Koo, Effect of temperature on the anisotropic superplasticity of textured Ti-25Al-10Nb alloy, Scripta Metall. Mater. 38 (1998) 267.

[52] S. Lee, J. Lee, Comparison of superplastic predictions using 2D plane strain and 3D modeling, J. Mater. Manufacturing Processes 9 (1994) 45 .

[53] H.Y. Wu, J.T. Chern, S. Lee, Superplastic forming of an Al-Li-Cu$\mathrm{Mg}-\mathrm{Zr}$ alloy using varied forming paths, J. Mater. Manufacturing Processes 10 (1995) 1 .

[54] S. Lee, Thickness distribution in a superplastically formed rectangular pan under plane strain conditions, J. Mater. Processing Technol. 65 (1997) 59

[55] S.C. Chang, J.W. Yeh, D.C. Luu, The superplasticity of Al-Li Alloys, in: M. Peters, P.-J. Winkler, (Eds.), Aluminium-Lithium 6, DGM, Germany, 1992, p. 1047.

[56] S.C. Chang, D.C. Luu, T.C. Chen, Phenomenological reasoning for tensile superplasticity, in: T.H. Chuang, J.C. Huang, (Eds.), Proc. Workshop on Superplastic Forming and Diffusion Bonding, Taipei, 1994, p. 276.

[57] C.T. Ke, A study of the superplasticity of $\mathrm{Zn}-22 \mathrm{Al}-0.5 \mathrm{Cu}$ alloy fabricated by reciprocal extrusion, M.Sc. Thesis, National Tsing Hua University, Taiwan, 1997.

[58] S.Y. Yuan J.W. Yeh, The improved microstructures and properties of 2024 alloy produced by reciprocal extrusion method, in: T. Chandra, T. Sakai (Eds.), Proc. Thermec '97, TMS, Warrendale, PA, USA, 1997, p. 1143.

[59] J.Y. Uan, L.H. Chen, T.S. Li, A study on the subgrain superplasticity of extruded $\mathrm{Al}-\mathrm{Al}_{3} \mathrm{Ni}$ eutectic alloy, Metall. Mater. Trans. 28A (1997) 401.

[60] J.Y. Uan, L.H. Chen, T.S. Lui, Plastic inhomogeneity and easy glide of aluminum and $\mathrm{Al}_{-} \mathrm{Al}_{3} \mathrm{Ni}$ eutectic alloy with [ $\left.\begin{array}{llll}1 & 1 & 1\end{array}\right]$ fiber texture, Acta Mater. 45 (1997) 623.

[61] J.P. Chu, I.M. Liu, J.H. Wu, W. Kai, J.Y. Wang, K. Inoue, Superplastic deformation in coarse-grained Fe-27Al alloys, Mater. Sci. Eng., 1998, in press. 
[62] T. Imai, G. L’Esperance, B.D. Hing, S. Kojima, High strain rate superplasticity of AlN particulate reinforced IN 90 pure aluminum composite, Scripta Metall. Mater. 33 (1995) 1333.

[63] K.C. Tien, Aero industry development center, 1998, private communication.

[64] A. Inoue, T. Zhang, Novel superplasticity of supercooled liquid for bulk amorphous alloys, Mater. Sci. Forum 243-245 (1997) 197.
[65] R.J. Gottschall, Structure and properties of bulk amorphous alloys, Metall. Mater. Trans. 29A (1998) 1777.

[66] R.Z. Valiev, D.A. Salimonenko, N.K. Tsenev, P.B. Berbon, T.G. Langdon, Observations of high strain rate superplasticity in commercial aluminum alloys with ultrafine grain sizes, Scripta Mater. 37 (1997) 1945. 